Brit. f. vener. Dis. (1971) 47, 177

\title{
Nitrimidazine in the treatment of Trichomonas vaginalis vaginitis
}

\author{
L. COHEN \\ Cardiff Royal Infirmary, Newport Road, Cardiff
}

Metronidazole has been the treatment of choice for trichomoniasis for more than 10 years. Carneri and co-workers (1969) described another nitromidazole compound 'nitrimidazine' (1-N (B-ethylmorpholine)5-nitroimidazole) which was found to be active systemically after oral administration. They demonstrated that effective trichomonicidal levels in urine and blood could be obtained after oral ingestion of $250 \mathrm{mg}$. of the compound, and further suggested that nitrimidazine was active topically.

A clinical trial of the systemic efficacy of this compound is reported below.

\section{Method}

100 women attending a venereal diseases clinic who were found to be harbouring $T$. vaginalis in the vaginal secretion were each given one tablet of $250 \mathrm{mg}$. nitrimidazine orally twice daily for 6 days. Where possible, their sexual partners were also given the same dosage of the drug.

Diagnosis was based on detection of the parasite in a 'hanging drop' sample of the vaginal secretion and on culture in Feinberg-Whittington medium. The patients were later re-examined, by the hanging drop method at the least, on the 2nd and 6th days after starting to take the drug, and culture was carried out 4 to 6 weeks after the completion of treatment. Patients who failed to return for final assessment of cure by culture were excluded from the trial.

In the course of the investigation, urethral, cervical, and in many cases, rectal secretions were examined by smears and culture to detect the presence of $N$. gonorrhoeae and $C$. albicans.

\section{Case data and findings}

The patients remained under observation for an average of 85.3 days (range 58 to 121). The average number of examinations per patient was five, and the average number of cultures for $T$. vaginalis was three per patient. The age distribution of the 63 patients who completed the trial satisfactorily was as follows:

Received for publication October 9, 1970

\begin{tabular}{lr}
\hline Age of patient (yrs) & No. treated \\
$0-16$ & 4 \\
$16-20$ & 23 \\
$20-25$ & 23 \\
$25-30$ & 6 \\
$30-50$ & 5 \\
$50+$ & 2 \\
\hline
\end{tabular}

As would be expected in a sample taken in venereal diseases clinic, most of the patients wert aged from 16 to 25 years, and belonged to the most sexually active group in the community. Sixteen were married. In 33 cases the consorts were not treated, and reliance had to be placed on the patients' sexual continence to avoid re-infection, which could be confused with failure of treatment.

The initial symptoms of the patients were not graded, but an objective assessment of the vaginitis was attempted by estimating both the extent of the vaginal secretion and the numbers of trichomonads in the hanging drop and culture specimens; the earlier were noted as absent, slight, abundant, and very abundant, as in the following Table:

\begin{tabular}{lll}
\hline Vaginal secretion & $\begin{array}{l}\text { Microscopical } \\
\text { examination of } \\
\text { fresh material }\end{array}$ & \\
\cline { 2 - 3 } & 4 & Extent \\
\hline 6 & 9 & Absent \\
22 & 25 & Slight \\
24 & 25 & Abundant \\
\hline
\end{tabular}

In the cases of the six women in whom there was no excess vaginal secretion, it was possible to culture Trichomonas vaginalis; in four of these cases the protozoon had not been seen in the wet film.

There was no close correlation between the appearance of the vaginal epithelium and the abundance of trichomonads, and in some cases in which trichomonads were abundant there was no obvious 
vaginitis. The patients' subjective symptoms of irritation or discharge bore very little relationship either to the amount of secretion or to the abundance of organisms.

\section{Other diagnoses in the 63 cases}

There were 37 cases with Trichomonas vaginalis only, nineteen also harboured $N$. gonorrhoeae, and seven also harboured $C$. albicans.

The concomitant appearance of Trichomonas vaginalis and $N$. gonorrhoeae is to be expected, but the number of cases in which $C$. albicans was found was comparatively small.

At the completion of the trial it was found that, of the 63 women completing treatment, only one failed to be cured, so that the success rate was 98 per cent.

\section{Discussion}

Although an unusually high cure rate was obtained, it is emphasized that these 63 patients were likely to be more reliable, in that all remained under surveillance for final cultural tests of cure. Furthermore, nearly half of the sexual partners were also treated. Emanueli and Carneri (1969) reported a 7 per cent. incidence of minor side-effects, such as nausea, but in our series there were no untoward reactions at all. All our patients were advised to take the drug after meals. No intolerance to alcohol was observed and there was no complaint of 'bitterness' after smoking cigarettes. Eight women known to be suffering from hypertension showed no rise in either systolic or diastolic blood pressure while taking nitrimidazine. It is of interest to note that in the one case of failure there was also no success with metronidazole. It was subsequently shown by spectrographic studies that in this patient there was metabolism of both drugs into non-active constituents before they could reach the trichomonads in the vagina. The organisms isolated from this patient were fully sensitive in vitro to both substances.

Those women who presented with severe irritation responded to nitrimidazine 2 days later than a comparable group taking metronidazole. Active trichomonads, as seen in the hanging drop specimens, persisted longer in the vaginal secretion in those treated with nitrimidazine than in those treated with metronidazole. This observation bore no relationship to the abundance either of the vaginal secretions or of the trichomonads.

There appeared to be no predisposition for an overt candidiasis to emerge in patients taking nitrimidazine, and as in the case of those taking metronidazole there was a tendency to 'unmask' an underlying gonococcal infection after the cure of the trichomoniasis.

\section{Summary}

Nitrimidazine was administered orally to 100 women found to be harbouring Trichomonas vaginalis. The dose was $250 \mathrm{mg}$. twice daily for 6 days. Diagnosis and tests for cure were by smears and cultures in Feinberg-Whittington medium and, of the 63 women completing surveillance, 62 were cured. There were no side-effects.

On the basis of this small series, nitrimidazine appears to be useful in the treatment of vaginal trichomoniasis.

I should like to thank Carlo Erba (U.K.) Ltd. for the supplies of nitrimidazine, and my clinic sister, Mrs. J. Hughes, without whose help the trial would not have been possible.

\section{References}

DE CARNERI, I., et al (1969) 6th International Congress of Chemotherapy, Tokyo, August 1969.

EMANUELI, A., and DE CARNERI, I. (1969) 6th International Congress of Chemotherapy, Tokyo, August 1969

\section{Le traitement de la trichomonase par le Nitrimidazine}

\section{SOMMAIRE}

Le Nitrimidazine a été donné par voie orale à 100 femmes trouvées porteuses de Trichomonas vaginalis. $\mathrm{La}$ dose a été de $250 \mathrm{mg}$. dẹux fois par jour, pendant 6 jours. Le diagnostic et les contrôles de guérison furent effectués sur lame et par culture sur milieu Feinberg-Whittington; sur les 63 femmes s'étant soumises à la surveillance, 62 furent guéries. Il n'y eut pas d'effet secondaire.

D'après cette petite série, le Nitrimidazine semble très utile dans le traitement de la trichomonase vaginale. 